\title{
Association of Diabetes Complications With Depression and Suicidality in Hospitalized Patients: a Multicenter Cross-sectional Study
}

\section{Majid Pakdin}

Shiraz University of Medical Sciences

Alireza Ebrahimi

Shiraz University of Medical Sciences

Mohammadsaeed Gharaati Jahromi

Shiraz University of Medical Sciences

Ali Firoozabadi ( $\square$ ali.firoozabadi.md@gmail.com )

Hafez Hospital, Shiraz University of Medical Sciences

\section{Research Article}

Keywords: Depression, Diabetes Mellitus, Suicidal ideation

Posted Date: February 15th, 2022

DOI: https://doi.org/10.21203/rs.3.rs-1086867/v3

License: (c) (i) This work is licensed under a Creative Commons Attribution 4.0 International License.

Read Full License 


\section{Association of Diabetes Complications with Depression and Suicidality in Hospitalized Patients: A Multicenter Cross-sectional Study}

Authors: Majid Pakdin, MD ${ }^{1}$, Alireza Ebrahimi, MD ${ }^{1}$, Mohammadsaeed Gharaati Jahromi, MD, $\mathrm{MPH}^{1}$, Ali Firoozabadi, $\mathrm{MD}^{2 *}$

1- Student Research Committee, Shiraz University of Medical Sciences, Shiraz, Iran

2- Department of Psychiatry, Shiraz University of Medical Sciences, Shiraz, Iran

* Corresponding author:

Ali Firoozabadi, M.D

Associate Professor of Psychiatry and Behavioral Sciences

Address: Hafez Hospital, Department of Psychiatry, Shiraz University of Medical Sciences, Shiraz, Iran

Email: ali.firoozabadi.md@gmail.com

Running title: Depression and suicidality among diabetic patients 


\begin{abstract}
Objective: The present study aimed to compare the prevalence of depression symptoms and suicidal ideation between diabetic patients admitted at hospital and healthy individuals. It also aimed to determine the relationship between types of diabetes complications and severity of symptoms.
\end{abstract}

Method: A total of 89 patients, who were admitted to the hospital because of the complications of the disease, were voluntarily and conveniently participated in the study. The participants were given the questionnaires of Beck Depression Inventory-2nd-edition and Beck Scale for Suicide Ideation. They were divided into two age groups: 18-50 years old and 50-75 years old. Control group, consisting of 89 individuals without any underlying disease, were randomly selected from the patients' visitors, matched with the participants according to the age group and gender. Statistical analysis was performed between the two groups based on scores obtained.

Results: Beck Depression Inventory Scale score was significantly higher, regardless of age, in the patient group compared to the control group. However, there was no significant difference between the scores of Beck Scale for Suicide Ideation between the patient group and the control group. In the patient group, it was found that among the variables, female gender, and diabetic foot were associated with higher severity of depression symptoms.

Conclusion: It is vitally essential for diabetic patients to undergo periodic psychiatric evaluation. Early diagnosis of depression could help them to better cope with their mental health issue, and as a result, it will decrease risk of suicidal ideation and other consequences.

Key words: Depression; Diabetes Mellitus; Suicidal ideation 


\section{Introduction}

Diabetes mellitus (DM) is a group of metabolic disorders characterized by elevated blood glucose levels caused by insulin production and, or action deficiencies. The disease could lead to several consequences, including generalized vascular damages of different organs such as eyes, kidneys, heart, and nerves, resulting in life-threatening complications [1]. Over the past few decades, the prevalence of DM in adults has been growing drastically, as individuals have become less active due to the modernization of lifestyles [2]. In a way that is predicted the number of patients with diabetes will be reached at 578 million by 2030, globally [3]. In addition, the International Diabetes Federation (IDF) has estimated that 23 million years of life had been lost because of DM complications, including reduced quality of life (QoL), and related disabilities [4].

Depression is considered the most prevalent mental health condition in the general population [5]. It has been mentioned that more than 264 million individuals of all age groups are suffering from depression, worldwide [6]. This has led to an enormous burden on the healthcare system because depression might have many fatal and non-fatal consequences [7]. Besides, depression can also result in lowered work productivity and increased need for healthcare resources [8]. Lastly and most certainly not least, the condition can lead to an increased risk of mortality caused by suicide in its most severe form [9-11].

The comorbidity of depression and diabetes has been a subject that many researchers were eager to investigate in many countries [12]. Since the frequencies of two are tended to be rapidly increased [12]; besides, it is estimated that the rate of depression is nearly doubled in diabetic patients compared with the general population [13,14]. Moreover, depression in patients with DM is usually more consistent and is frequently accompanied by more somatic symptoms, decreased QoL, increased disability, increased mortality risk, and increased healthcare costs [15]. In fact, 
chronic psychological stressors, such as DM, could be the underlying cause of the higher rate of depression in these patients [4]. Moreover, the presence of comorbid consequences related to DM and the resulted disabilities may be responsible for the higher rate of depression in diabetic patients [16]. However, it is worth mentioning that the exact underlying mechanisms that lead to this increased rate of depression in diabetic patients are yet to be found [17].

Several studies have been done in the world, including Iran, to evaluate the prevalence of depression in diabetic patients. However, to the best of our knowledge, there is no project assessing the prevalence of depression and suicidal ideation concurrently in diabetic patients in Iran. In this cross-sectional study, we aim to estimate the prevalence of suicidal ideation and severity of depression symptoms and their associations among the patients diagnosed with DM, and were admitted to hospital because of the disease's complications. In addition, we aim to estimate the prevalence of depression and suicidal ideation in patients with different types of DM complications.

\section{Methods}

\section{Design of Study, Participants, and Data Collection}

A cross-sectional survey was conducted on diabetic patients aged between 18-75 years old, who were admitted to the hospital because of the complications of the disease during a 5-month period. Data collection was done in three referral hospitals of Shiraz city, including Namazi hospital, Shahid Faghihi hospital, and Ali-Asghar hospital. The inclusion criteria were an age range of 1875 years, hospitalization for at least 24 hours, type 1 of diabetes mellitus (T1DM) or type 2 of diabetes mellitus (T2DM) diagnosis before the study, and willingness to participate in the research. The exclusion criteria were not being aware of their illness, low level of consciousness, and 
admission to the emergency ward. The patients who had been admitted due to macrovascular complications, such as cerebrovascular accidents, could not have been evaluated because of their health condition; therefore they were not included in this study.

A total number of 89 patients were voluntarily and conveniently participated in the study. They were given the Persian version of questionnaires of Beck Depression Inventory-2 ${ }^{\text {nd }}$-edition (BDIII) and Beck Scale for Suicide Ideation (BSS). In addition, socio-demographic information, including age, gender, and marital status were gathered. Besides, factors which are deemed to have an impact on the incidence of depression were asked, which were the duration of DM in the patients, type of DM, treatment with insulin, and the type of complication resulted from DM. The questionnaires were read and filled by trained interviewers for illiterate patients without any visitors. The duration of disease for patients who had been diagnosed with DM less than one year until participation was considered 0.25 year in order to make the analysis straightforward.

The participants were divided into two age groups: $18-50$ years old and 50-75 years old. The control group, consisting of 89 individuals without any underlying disease, was randomly selected from the patients' visitors, matched with the participants according to the age group and gender. The controls were determined by this method as it is supposed that the patients and their visitors might be at the same socio-economic level; hence, the disturbing effect of different socioeconomic levels on the results could be minimized.

\section{Questionnaires}

BDI-II assesses the severity of depression symptoms. However, it is not considered a diagnostic tool for depression. Indeed, a standard clinical interview with the patient done by an expert clinician is needed for the diagnosis [18]. The cross- cultural reliability and concurrent validity of 
the BDI-II-Persian as a measure of depressive symptoms in non-clinical samples in Iran have been administered in previous studies [19]. BDI-II includes 21 items, and each item is rated on a 4-point scale (0-3) and evaluates one of the symptoms related to depression, yielding summary scores that range from 0 to $63(18,20)$. BDI-II scoring classifies the answerers into three categories of individuals with normal or mild depression symptoms (0-16), borderline or moderate depression symptoms (17-31), and severe or very severe depression symptoms (31-63) [21]. The participants who were categorized as having moderate or severe depression symptoms were advised to consult with an expert clinician for further evaluation.

BSS is based on 19 questions that can evaluate the risk of suicide attempt [22]. It has been shown that the Persian translation of the BSS has desirable psychometric properties in the research settings [23]. Each item in this questionnaire is scored based on an ordinal scale from 0 to 2 , and the total score is 0 to 38 . Generally, the first five questions are screening items that evaluate the patients' general feelings about life and death, and also the desire to suicide. In case of any active or passive ideation about suicide, the participants should answer the following fourteen questions. These patients were immediately referred to visit a consultant as the risk of suicide was considerably high. No cut-off point has been defined to categorize the scores of this questionnaire [22]. Therefore, the scores of the screening part (first fifth items) and the total scale (in cases with suicidal ideation) have been used for the data analysis of our study.

\section{Statistical Analysis}

All statistical analysis was performed using SPSS 21.0. Mean and the standard deviation (SD) was used to present continuous variables, while categorical variables were shown as numbers and percentage. Since the distribution of inputs was not normal, univariate analysis was done using nonparametric tests of Mann-Whitney, Kruskal-Wallis, and Spearman's rank correlation 
coefficient. Multivariable analysis was also done after checking collinearity and variance inflation factors using logistic regression (Enter method). P-value $\leq 0.05$ was considered statistically significant.

\section{Ethical statement and consent to participate}

All subjects provided written informed consent while voluntarily participation in all stages of this study was respected. Privacy was assured in all steps of study, including filling the questionnaires, data collection, recording, analysis, and reporting. All institutional and national guidelines were

followed; besides, the study protocol was approved by the institutional research board (IRB) of the medical ethics committee of Shiraz University of Medical Sciences (SUMS), Shiraz, Iran (Reg. No: IR.SUMS.REC.1396.S183).

\section{Results}

The total number of 89 patients participated in this study, that $46(51.7 \%)$ were male and 43 (48.3\%) were female. The age group of 18-50 years old consisted of 26 (29.2\%) participants, and 50-75 years old was consisted of 63 (70.8\%) participants. As previously mentioned, the control group was matched with the patient groups based on age and gender.

Among all the participants, who were hospitalized because of different DM sequelae, 53 (59.6\%) had diabetic foot, 21 (23.6\%) had diabetic nephropathy, 9 (10.1\%) had diabetic ketoacidosis (DKA), and 6 (6.7\%) had pneumonia. Besides, 21 (23.6\%) of these patients had been diagnosed with T1DM, and 68 (76.4\%) were suffering from T2DM. Out of 89 patients, 63 (70.8\%) patients had been using insulin as part of their routine treatment before the hospital admission, compared to $26(29.2 \%)$ patients who had not been under treatment with insulin before hospital admission (Table 1). 
In the patient group, the minimum score of BDI-II was zero, and the maximum was 48 . The mean BDI_II score of all diabetic patients was measured as $17.07 \pm 10.84$ (Table 2). Moreover, the minimum score of BSS was zero, the maximum was 26 , and the mean was also calculated as $1.71 \pm 5.18$ for these patients. BDI-II scores of normal individuals were between zero to 32 , and the mean score was $6.74 \pm 5.73$. Furthermore, the minimum, maximum, and mean BSS scores of normal individuals were calculated to be zero, 9 , and $0.69 \pm 1.35$, respectively (Table 2).

Considering the age group of 18-50-year old and based on Mann-Whitney U Test, the mean rank of BDI-II scores was 33.40, which was significantly higher than the control (P value=0.001). However, the mean rank of BSS scores in these patients did not have a considerable difference in comparison with the control group ( $\mathrm{P}$ value=0.387) $($ Table 3). The reason of using Mann-Whitney $\mathrm{U}$ test for the analysis was that the distribution of participants regarding their age was not normal. The same pattern was observed for the age group of 50-75 years old, as the mean rank of BDI-II scores was 84.48 for the patient group and 45.52 for the matched control ( $\mathrm{P}$ value $<0.001)$; also, the mean rank of BSS scores in the patient group and the control group were 63.48 and 63.52 , respectively $(\mathrm{P}$ value$=0.993)($ Table 3$)$.

Moreover, the mean rank of BDI-II scores in the males between 18-50 years old was 18.63 which was statistically different from the controls ( $\mathrm{P}$ value=0.05); while, the mean rank of BSS scores in these patients was not significantly different compared with the controls (P value $=0.653)$. Similar patterns were seen for 18-50 years old female participants (mean rank of BDI-II score=15.32 with $\mathrm{P}$ value $=0.004$, and mean rank of $B S S$ scores $=10.82$ with $\mathrm{P}$ value $=0.652$ ), $50-75$ years old male participants (Mean rank of BDI-II scores $=40.74$ with $\mathrm{P}$ value $<0.001$, and mean rank of BSS score $=30.55$ with $\mathrm{P}$ value $=0.547$ ), and also female participants of 50-75-year old (mean rank of BDI-II scores $=44.42$ with $\mathrm{P}$ value $<0.001$, and mean rank of BSS scores $=33$. with $\mathrm{P}$ value $=0.633$ ). 
Meaning that all these diabetic patients with different genders had significantly higher BDI-II scores compared to their matched groups; however, the mean rank BSS scores of normal individuals and the mentioned patients was not statistically different (Table 3).

Overall, 39 (43.8\%) participants (5 males 18-50 years old, 6 females of 18-50 years old, 9 males of 50-75 years old, and 19 females of 50-75 years old) obtained BDI-II score of above 16, which means they are at risk of depression. In the control group, there were only four individuals who obtained BDI-II score of above 16, two of them were males of 50-75 years old and the other two were females of 50-75 years old (Table 4). Regarding the BSS, 5 (5.6\%) patients (2 males of 1850-years old, 2 females of 50-75 years old, and 1 female of 18-50 years old) did not give the negative answer to the questions, meaning that they are at risk of a suicide attempt. While, in the control group, only one (1.1\%) of the participants did not give the negative answer to this question who was female of 50-75 years old (Table 4). The results of the present study showed that the individuals who had higher scores of BDI-II scores would probably have higher BSS both in the diabetic patient group and the normal control group ( $\mathrm{P}$ value $<0.001$ ).

The mean rank of BDI-II scores for patients between 18 to 50 years old was 42.75 , and 45.93 for patients between 50 to 75 years old (Table 5). Besides, the mean rates of BSS in the patients of 18-50-year-old were 44.29, and 43.13 in the patients of 50-75-year-old (Table 5). The present study found that the scores of BDI-II and BSS in the diabetic patients are not associated with the patients' ages $(\mathrm{P}$ value $=0.597$, and $\mathrm{P}$ value $=0.828)$.

Considering the gender of participants, the mean rank of BDI-II scores in the males was 38.63 , and 51.81 in the females. According to these scores, the females are more vulnerable to be suffered from depression (P value=0.016) (Table 5). However, as shown in Table 5, there was no significant 
difference between the mean rank of BSS scores in the male patients (41.16) and female patients (49.10) $(\mathrm{P}-$ value=0.060).

According to the results of the present study, the duration of being diagnosed with DM, the type of DM, and usage of insulin do not affect the rates of BDI-II and BSS (Table 5). However, it was found that the type of complication could comparably differ the BDI-II scores (P value=0.005), and the patients who had diabetic foot were at higher risk of growing depression based on KruskalWallias test. $(\mathrm{P}$ value=0.026) $($ Table 5).

\section{Discussion}

The prevalence of DM has been rapidly increasing since a few decades ago because of the population aging. Besides, the sedentary lifestyles and unhealthy habits, particularly in low-andmiddle income countries. DM has become a global public health concern, causing substantial harm to public health and socio-economic development. Moreover, the disease is considered as one of the top ten causes of mortality worldwide, and the second major reason diminishing the overall health adjusted life expectancy [24]. Frequently, diabetes is accompanied by various physical sequelae, such as cardiovascular diseases and diabetic foot, as well as psychological conditions, for instance, anxiety and depression [25].

The results of the present investigation illustrated that diabetic patients, regardless of their ages, are at higher risk of growing depression. Similarly, previous studies have also shown that the prevalence of depression symptoms in patients with DM is nearly as twice as in the general population [26]. According to our findings, $43.8 \%$ of the diabetic patients had moderate to very severe depression symptoms. In another study evaluating the depressive symptom in a group of Iranian diabetic patients with the same assessment tool, it has been found that $40.6 \%$ of the patients 
had moderate to very severe depression symptoms, which is comparable to our findings [27]. However, the cut-off score of 21 in BDI-II has been considered for having moderate depression symptoms in the mentioned study, while we considered a cut-off score of 17 in our study. In addition, only diabetic patients been admitted to the hospital were included in our study, which could explain the higher rate of depression symptoms in these patients. Mirzaei, et al. revealed that $29.4 \%$ of diabetic patients had been suffering from moderate to severe depression, but DASS-21 questionnaire has been used as an assessment tool in their study [28]. Overall, it seems that the rate of depression in Iranian diabetic patients is higher compared to the findings obtained in developed countries $[29,30]$. This difference may be due to socio-economic status in our country.

The definite underlying pathophysiology of comorbidity of DM and depression is yet to be found; however, several theoretical models have been proposed. For example, it has been mentioned that changes in brain function caused by biological changes and chronic inflammation that occur during DM could lead to depression [31, 32]. Additionally, the cerebral microvascular dysfunction, that is found to be presented even in individuals with prediabetes, could be another cause of this higher prevalence of depression among diabetic patients [33]. The results of our study are also consistent with prior investigations, which mentioned that women with diabetes are at higher risk of developing depression than men [8]. This could be described by the fact that women commonly involve with more negative life experiences, and by the different hormonal and genetic factors. Moreover, our investigation has found that the type of complication is associated with the likelihood of depression incidence. Patients who had diabetic foot were more likely to have higher BDI-II scores. It has been previously indicated that the type of DM complications, including nephropathy, neuropathy, retinopathy, and sexual dysfunction, has significant relationship with depressive symptoms [34]. Regarding the patients with diabetic foot, reports showed that more 
than one-third of the patients suffer from depression [35]. Subsequently, it seems that the female diabetic patients, and the patients with severe complications of DM, such as diabetic foot, require special attention and exceptional support to prevent depression.

Considering treatment with insulin, Hermanns, et al. found that the prevalence of depression was significantly higher in the patients with T2DM who were using insulin as part of their routine treatment [36]. Similarly, our findings showed that the scores of BDI-II obtained by insulin users were higher than non-insulin users, although this difference was not significant. It seems that insulin using could be an indicator of DM severity and progression in diabetic patients, which can increase the risk of depression in these patients. In our study, the higher scores of BDI-II were also observed in the patients with T2DM compared to the patients with T1DM, which is consistent with the finding of a previous meta-analysis (8), although this difference was not significant in both studies. This difference is maybe due to the fact that patients with T1DM have been more successful in adapting themselves to the disease as their diseases have been diagnosed at a younger age.

Earlier epidemiological findings noticed that there might be a reciprocal causal relationship between depression and diabetes [37]. Meaning that depression is found to be a risk factor for the progression of diabetes, and DM is labeled as a risk factor for the development of depression [38]. Probably, this could be explained by the adverse effects that depression symptoms have on the healthy behaviors and activity levels of individuals [37]. It is worth mentioning that a diagnosis of DM and administration of therapies for DM have also been found to increase the incidence of depression [37]. Also, a meta-analysis done by Park, et al. showed that diabetic patients suffering from depression have significantly higher rates of all-cause mortality compared with those who do not have depressive symptoms [39]. Having said that, depression is a risk factor for non-suicidal 
mortality because it could negatively affect the patients' medical morbidity [40]. In addition to this, depression is a strong risk factor for externally caused mortalities, including suicide [41].

Considering the suicidal thoughts, the results of our study showed that nearly $6 \%$ of diabetic patients have suicidal ideations, and the patients who had higher scores of BDI-II were more susceptible to suicidality. A previous meta-analysis has indicated that diabetes can significantly raise the risk of suicide among the patients, particularly in those with T1DM [42]. Another comprehensive investigation also mentioned that the frequency of suicidality is majorly higher in diabetic patients who access fatal means, such as insulin and oral hypoglycemic agents, which have already been provided for them. In fact, they are at danger of self-harm [43]. However, according to the rates of BSS, measured among patients with DM in the current investigation, there is no significant difference between the risk of suicide amongst the diabetic patients and normal individuals. Moreover, we did not find any significant association between the suicidality with neither the gender of patients nor the type of DM and nor the usage of insulin. These contradictory results could be because of the different sample sizes and study periods, and cultural and environmental factors. In addition, low numbers of items (5 questions), which are generally answered in this questionnaire, could have affected the results. Supposedly, since the physical and mental comorbidities were estimated to be more prevalent in patients with DM, that might lead to functional disabilities and lowered QoL, the progression of depression could eventually result in suicide attempt done by these patients [44]. Therefore, we believe that the possibility of an increased risk of suicide among diabetic patients should not be underestimated, and more studies are needed in this regard.

Diabetes, depression, and suicide are all among global health concerns that have excessively burdened the healthcare systems, governments, and societies all around the world. The prevalence 
of all these three problems is soaring as a result of distorted lifestyles caused by rapid modernization and urbanization. Furthermore, depression is seemed to have a complex interrelationship with chronic diseases, including diabetes. Meaning that it could act as a factor that precipitates the development of the disease, and also be exacerbated because of the disabilities caused by the disease. This is an alarming vicious cycle that could increase the rate of both morbidity and mortality in diabetic patients; besides, as known, depression could lead to suicide, eventually. These facts indicate that the clinicians should regularly evaluate the diabetic patients' mental condition, and screening and detecting depression symptoms should be done in these patients as early as possible.

\section{Limitations of Study}

Since our study was cross-sectional, patients with risk of depression and suicide have not been followed up, although they have been referred to a psychiatrist. In addition, all of DM complications have not been evaluated in this study, as many diabetic patients with complications such as sexual dysfunction and retinopathy are visited on an outpatient basis and do not be admitted to the hospital.

\section{Conclusion}

This study and past investigations indicate that the risk of depression and suicide in diabetic patients should not be overlooked. When it comes to female patients with disabling complications such as diabetic foot, this risk is even multiplied. As a result, it is vitally important for diabetic patients to undergo periodic psychiatric evaluation. Early diagnosis of depression could help them to better cope with their mental health issue, and thus, it will prevent suicidal ideation and other consequences. 


\section{Acknowledgement}

The authors are very grateful to diabetic patients who participated in this study.

\section{Declaration of Conflicting Interests}

The author(s) declared no potential conflicts of interest with respect to the research,

authorship, and/or publication of this article.

\section{Funding}

This project has been funded by SUMS

\section{References}

1. Baena-Díez JM, Peñafiel J, Subirana I, Ramos R, Elosua R, Marín-Ibañez A, et al. Risk of Cause-Specific Death in Individuals With Diabetes: A Competing Risks Analysis. Diabetes Care. 2016;39(11):1987.

2. Cho NH, Shaw JE, Karuranga S, Huang Y, da Rocha Fernandes JD, Ohlrogge AW, et al. IDF Diabetes Atlas: Global estimates of diabetes prevalence for 2017 and projections for 2045. Diabetes Research and Clinical Practice. 2018;138:271-81.

3. Saeedi P, Petersohn I, Salpea P, Malanda B, Karuranga S, Unwin N, et al. Global and regional diabetes prevalence estimates for 2019 and projections for 2030 and 2045: Results from the International Diabetes Federation Diabetes Atlas. Diabetes research and clinical practice. 2019;157:107843. 
4. Egede LE, Ellis C. Diabetes and depression: Global perspectives. Diabetes Research and Clinical Practice. 2010;87(3):302-12.

5. Lim GY, Tam WW, Lu Y, Ho CS, Zhang MW, Ho RC. Prevalence of depression in the community from 30 countries between 1994 and 2014. Scientific reports. 2018;8(1):1-10.

6. Depression January, 302020 [Available from: https://www.who.int/news-room/factsheets/detail/depression.

7. The World Health Organization. The Global Burden of Disease: 2004 Update. 2008.

8. Anderson RJ, Freedland KE, Clouse RE, Lustman PJ. The prevalence of comorbid depression in adults with diabetes: a meta-analysis. Diabetes Care. 2001;24(6):1069-78.

9. Choo C, Diederich J, Song I, Ho R. Cluster analysis reveals risk factors for repeated suicide attempts in a multi-ethnic Asian population. Asian journal of psychiatry. 2014;8:38-42.

10. Large M. Study on suicide risk assessment in mental illness underestimates inpatient suicide risk. Bmj. 2016;352.

11. Cuijpers P, Smit F. Excess mortality in depression: a meta-analysis of community studies. Journal of affective disorders. 2002;72(3):227-36.

12. Sartorius N. Depression and diabetes. Dialogues in clinical neuroscience. 2018;20(1):47.

13. Anderson RJ, Freedland KE, Clouse RE, Lustman PJ. The prevalence of comorbid depression in adults with diabetes: a meta-analysis. Diabetes care. 2001;24(6):1069-78. 
14. Ali S, Stone M, Peters J, Davies M, Khunti K. The prevalence of co-morbid depression in adults with Type 2 diabetes: a systematic review and meta-analysis. Diabetic medicine. 2006;23(11):1165-73.

15. Campayo A, Gómez-Biel CH, Lobo A. Diabetes and Depression. Current Psychiatry Reports. 2011;13(1):26-30.

16. De Jonge P, Roy J, Saz P, Marcos G, Lobo A. Prevalent and incident depression in community-dwelling elderly persons with diabetes mellitus: results from the ZARADEMP project. Diabetologia. 2006;49(11):2627-33.

17. Nouwen A, Winkley K, Twisk J, Lloyd CE, Peyrot M, Ismail K, et al. Type 2 diabetes mellitus as a risk factor for the onset of depression: a systematic review and meta-analysis. Springer; 2010.

18. Beck AT, Steer RA, Brown G. Beck depression inventory-II. Psychological Assessment. 1996.

19. Ghassemzadeh H, Mojtabai R, Karamghadiri N, Ebrahimkhani N. Psychometric properties of a Persian-language version of the Beck Depression Inventory-Second edition: BDIII-PERSIAN. Depression and anxiety. 2005;21(4):185-92.

20. Dozois DJ, Dobson KS, Ahnberg JL. A psychometric evaluation of the Beck Depression Inventory-II. Psychological assessment. 1998;10(2):83.

21. Klass D, Silverman PR, Nickman S. Continuing bonds: New understandings of grief: Taylor \& Francis; 2014. 
22. Reinecke MA, Franklin-Scott RL. Assessment of suicide: Beck's scales for assessing mood and suicidality. Assessment, treatment, and prevention of suicidal behavior. 2005:29-61.

23. Esfahani M, Hashemi Y, Alavi K. Psychometric assessment of beck scale for suicidal ideation (BSSI) in general population in Tehran. Medical journal of the Islamic Republic of Iran. $2015 ; 29: 268$.

24. Lin X, Xu Y, Pan X, Xu J, Ding Y, Sun X, et al. Global, regional, and national burden and trend of diabetes in 195 countries and territories: an analysis from 1990 to 2025 . Scientific reports. 2020;10(1):1-11.

25. de Groot M, Golden SH, Wagner J. Psychological conditions in adults with diabetes. Am Psychol. 2016;71(7):552-62.

26. Sartorius N. Depression and diabetes. Dialogues Clin Neurosci. 2018;20(1):47-52.

27. Taziki S, Bazrafsan H, Behnampour N, Paviz M. Relationship between depressive's symptoms and diabetes. J Gorgan Univ Med Sci. 2001;3(2):59-64.

28. Mirzaei M, Daryafti H, Fallahzadeh H, Azizi B. Evaluation of depression, anxiety and stress in diabetic and non-diabetic patients. SSU_Journals. 2016;24(5):387-97.

29. Park CY, Kim SY, Gil JW, Park MH, Park J-H, Kim Y. Depression among Korean adults with type 2 diabetes mellitus: Ansan-community-based epidemiological study. Osong public health and research perspectives. 2015;6(4):224-32.

30. Kruse J, Schmitz N, Thefeld W. On the association between diabetes and mental disorders in a community sample: results from the German National Health Interview and Examination Survey. Diabetes care. 2003;26(6):1841-6. 
31. Holt RI, de Groot M, Golden SH. Diabetes and depression. Curr Diab Rep. 2014;14(6):491.

32. Firouzabadi A, Momeni T. Prevalence of Diabetes Mellitus in Hospitalized Patients with Bipolar Disorder. Iranian Journal of Psychiatry and Clinical Psychology. 2002;8(1):57-60.

33. van Sloten TT, Sedaghat S, Carnethon MR, Launer LJ, Stehouwer CD. Cerebral microvascular complications of type 2 diabetes: stroke, cognitive dysfunction, and depression. The lancet Diabetes \& endocrinology. 2020;8(4):325-36.

34. De Groot M, Anderson R, Freedland KE, Clouse RE, Lustman PJ. Association of depression and diabetes complications: a meta-analysis. Psychosomatic medicine. 2001;63(4):619-30.

35. Ahmad A, Abujbara M, Jaddou H, Younes NA, Ajlouni K. Anxiety and depression among adult patients with diabetic foot: prevalence and associated factors. Journal of clinical medicine research. 2018;10(5):411.

36. Hermanns N, Kulzer B, Krichbaum M, Kubiak T, Haak T. Affective and anxiety disorders in a German sample of diabetic patients: prevalence, comorbidity and risk factors. Diabetic Medicine. 2005;22(3):293-300.

37. Darwish L, Beroncal E, Sison MV, Swardfager W. Depression in people with type 2 diabetes: current perspectives. Diabetes Metab Syndr Obes. 2018;11:333-43.

38. Nouwen A, Adriaanse MC, van Dam K, Iversen MM, Viechtbauer W, Peyrot M, et al. Longitudinal associations between depression and diabetes complications: a systematic review and meta-analysis. Diabet Med. 2019;36(12):1562-72. 
39. Park M, Katon WJ, Wolf FM. Depression and risk of mortality in individuals with diabetes: a meta-analysis and systematic review. Gen Hosp Psychiatry. 2013;35(3):217-25.

40. Schulz R, Drayer RA, Rollman BL. Depression as a risk factor for non-suicide mortality in the elderly. Biol Psychiatry. 2002;52(3):205-25.

41. Zhang $\mathrm{J}, \mathrm{Li}$ Z. The association between depression and suicide when hopelessness is controlled for. Compr Psychiatry. 2013;54(7):790-6.

42. Wang B, An X, Shi X, Zhang JA. MANAGEMENT OF ENDOCRINE DISEASE:

Suicide risk in patients with diabetes: a systematic review and meta-analysis. Eur J Endocrinol. 2017;177(4):R169-r81.

43. Sarkar S, Balhara YPS. Diabetes mellitus and suicide. Indian journal of endocrinology and metabolism. 2014;18(4):468.

44. Pompili M, Lester D, Innamorati M, De Pisa E, Amore M, Ferrara C, et al. Quality of life and suicide risk in patients with diabetes mellitus. Psychosomatics. 2009;50(1):16-23. 


\begin{tabular}{|c|c|c|}
\hline Item & & Frequency \\
\hline \multirow[t]{2}{*}{ Gender } & Male & $46(51.7 \%)$ \\
\hline & Female & $43(48.3 \%)$ \\
\hline \multirow[t]{2}{*}{ Age Group } & $18-50$ years old & $26(29.2 \%)$ \\
\hline & 50-75 years old & $63(70.8 \%)$ \\
\hline Type of & Diabetic Foot & $53(59.6 \%)$ \\
\hline \multirow[t]{4}{*}{ Complication } & Diabetic & $21(23.6 \%)$ \\
\hline & Nephropathy & \\
\hline & DKA & $9(10.1 \%)$ \\
\hline & Infection & $6(6.7 \%)$ \\
\hline \multirow[t]{2}{*}{ Type of DM } & Type 1 & $21(23.6 \%)$ \\
\hline & Type 2 & $68(76.4 \%)$ \\
\hline \multirow[t]{2}{*}{ Insulin Usage } & Insulin Users & $63(70.8 \%)$ \\
\hline & Non-Insulin Users & $26(29.2)$ \\
\hline
\end{tabular}




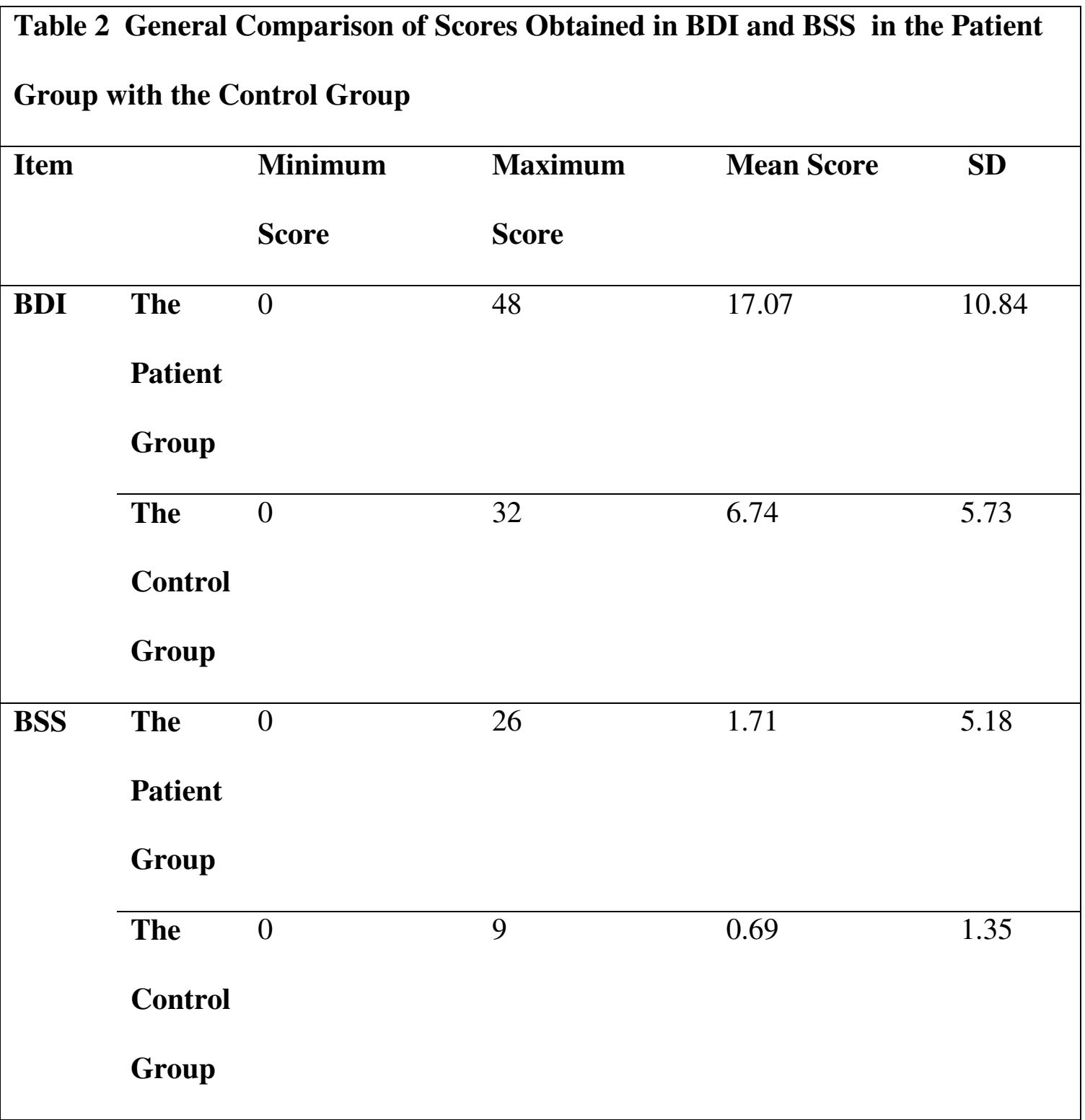




\begin{tabular}{|c|c|c|c|c|c|c|c|}
\hline Patient Grou & $p$ with th & Control & oup & & & & \\
\hline Item & $\begin{array}{l}\text { The } \\
\text { Patient } \\
\text { Group }\end{array}$ & $\begin{array}{l}\text { The } \\
\text { Control } \\
\text { Group }\end{array}$ & $\begin{array}{l}\text { P- } \\
\text { value }\end{array}$ & Item & $\begin{array}{l}\text { The } \\
\text { Patient } \\
\text { Group }\end{array}$ & $\begin{array}{l}\text { The } \\
\text { Control } \\
\text { Group }\end{array}$ & P-value \\
\hline $\begin{array}{l}\text { BDI in the } \\
\text { age group of } \\
18-50 \text { years } \\
\text { old }\end{array}$ & 33.40 & 19.60 & $0.001^{*}$ & $\begin{array}{l}\text { BDI in } \\
\text { females of } \\
18-50 \\
\text { years old }\end{array}$ & 15.32 & 7.68 & $0.004^{*}$ \\
\hline $\begin{array}{l}\text { BSS in the } \\
\text { age group of } \\
18-50 \text { years } \\
\text { old }\end{array}$ & 25.02 & 27.98 & 0.387 & $\begin{array}{l}\text { BSS in } \\
\text { females of } \\
18-50 \\
\text { years old }\end{array}$ & 10.82 & 12.18 & 0.652 \\
\hline $\begin{array}{l}\text { BDI in the } \\
\text { age group of } \\
50-75 \text { years } \\
\text { old }\end{array}$ & 88.48 & 45.52 & $<0.001^{*}$ & $\begin{array}{l}\text { BDI in } \\
\text { males of } \\
50-75 \\
\text { years old }\end{array}$ & 40.74 & 22.26 & $<0.001^{*}$ \\
\hline $\begin{array}{l}\text { BSS in the } \\
\text { age group of }\end{array}$ & 63.48 & 63.52 & 0.993 & $\begin{array}{l}\text { BSS in } \\
\text { males of }\end{array}$ & 30.55 & 32.45 & 0.547 \\
\hline
\end{tabular}




\begin{tabular}{|c|c|c|c|c|c|c|}
\hline $\begin{array}{l}\text { 50-75 years } \\
\text { old }\end{array}$ & & & $\begin{array}{l}50-75 \\
\text { years old }\end{array}$ & & & \\
\hline $\begin{array}{l}\text { BDI in } \\
\text { males of 18- } \\
50 \text { years old }\end{array}$ & $18.63 \quad 12.37$ & $0.05^{*}$ & $\begin{array}{l}\text { BDI in } \\
\text { females of } \\
50-75 \\
\text { years old }\end{array}$ & 44.42 & 20.58 & $<0.001^{*}$ \\
\hline $\begin{array}{l}\text { BSS in } \\
\text { males of } \\
18-50 \text { years } \\
\text { old }\end{array}$ & $14.73 \quad 16.72$ & 0.653 & $\begin{array}{l}\text { BSS in } \\
\text { females of } \\
50-75 \\
\text { years old }\end{array}$ & 33.45 & 31.55 & 0.633 \\
\hline
\end{tabular}




\begin{tabular}{|c|c|c|c|c|}
\hline \multicolumn{5}{|c|}{$\begin{array}{l}\text { Table } 4 \text { Comparison of Number of Individuals with the Risk } \\
\text { the Patient Group with the Ones in the Control Group }\end{array}$} \\
\hline Item & \multicolumn{2}{|c|}{ Frequency in the Patient } & \multicolumn{2}{|c|}{$\begin{array}{l}\text { Frequency in the Control } \\
\text { Group }\end{array}$} \\
\hline \multirow[t]{8}{*}{ Risk of Depression } & $39(43.8 \%)$ & 5 males of $18-$ & $4(4.5 \%)$ & 2 males of $50-$ \\
\hline & & 50 years old & & 75 years old \\
\hline & & 6 females of & & \\
\hline & & 18-50 years old & & \\
\hline & & 9 males of $50-$ & & 2 females of \\
\hline & & 75 years old & & $50-75$ years old \\
\hline & & 19 females of & & \\
\hline & & $50-75$ years old & & \\
\hline \multirow[t]{6}{*}{ Risk of Suicide Attempt } & $5(5.6 \%)$ & 2 males of $18-$ & $1(1.1 \%)$ & 1 female of $50-$ \\
\hline & & 50 years old & & 75 years old \\
\hline & & 1 female of 18 & & \\
\hline & & 50 years old & & \\
\hline & & 2 females of & & \\
\hline & & $50-75$ years old & & \\
\hline
\end{tabular}






